\title{
Pitfalls in processing home electronic spirometric data in asthma
}

\author{
H.K. Reddel, S.I. Ware, C.M. Salome, C.R. Jenkins, A.J. Woolcock
}

Pitfalls in processing home electronic spirometric data in asthma. H.K. Reddel, S.I. Ware, C.M. Salome, C.R. Jenkins, A.J. Woolcock. CERS Journals Ltd 1998.

ABSTRACT: Electronic spirometers offer the prospect of paperless home monitoring, but data quality is not automatically better than from conventional monitoring. The aim of this study was to determine the extent to which the quality and processing of self-recorded spirometric data from patients with asthma complied with international guidelines for spirometry.

Data were from 33 subjects with poorly controlled asthma who had completed the first 9 weeks of a clinical budesonide trial. MicroMedical DiaryCard electronic spirometers were used to record three spirometric manoeuvres in twice-daily sessions. Confounding events were recorded in a paper diary. Within-session reproducibility was calculated for forced expiratory volume in one second (FEV1), forced vital capacity (FVC) and peak expiratory flow (PEF) during the first week of run-in and week 9 of budesonide treatment.

Geometric means of within-session reproducibility (mean difference between highest and second-highest value from each session over a one-week period) for FEV1, FVC and PEF were $76 \mathrm{~mL}, 116 \mathrm{~mL}$ and $18 \mathrm{~L} \cdot \mathrm{min}^{-1}$, respectively, during run-in. Times of spirometric sessions varied widely, with some overlap between morning and evening session times. Manoeuvre-induced falls in PEF and FEV1 occurred only as often as expected by chance. Nonasthma events including equipment faults and painful conditions caused changes in spirometric results.

Home spirometric monitoring can be carried out with excellent reproducibility in patients with asthma. However, quality-control issues are complex and an accompanying paper diary remains essential.

Eur Respir J 1998; 12: 853-858.
Institute of Respiratory Medicine, Royal Prince Alfred Hospital and Dept of Medicine, University of Sydney, Camperdown, NSW, Australia.

Correspondence: H.K. Reddel

Institute of Respiratory Medicine

P.O. Box M77

Missenden Rd

Camperdown

NSW 2050

Australia

Fax: 61295506115

Keywords: Asthma

medical electronics

peak expiratory flow monitoring

reproducibility

spirometry

Received: July 281997

Accepted after revision March 171998

Funding for this study was supplied by Astra Pharmaceuticals and the National Health and Medical Research Council of Australia.
Ambulatory monitoring of peak expiratory flow (PEF) is used extensively in clinical asthma trials, in asthma management plans and in the diagnosis of occupational asthma [1-3]. In recent years, electronic monitoring devices have become available, enabling the recording and storage of PEF and sometimes of forced expiratory volume in one second (FEV1) and forced vital capacity (FVC). One of the major advantages of such devices is that the date and time are stored with each record, thereby eliminating falsification of results $[4,5]$, number preference [6] and transcription errors, which have been major sources of inaccuracy in the past. The widespread availability of computerized data processing has increased the attractiveness of electronic monitoring devices, particularly as they offer the possibility of paperless home monitoring.

However, a sophisticated electronic record of spirometric data from home monitoring is of little value if instrument error, software error or intrasubject variation is excessive. One study of computerized spirometers found software errors in $25 \%$ [7]. Intrasubject variation has been assumed to be higher for home spirometric monitoring than for supervised testing and for PEF manoeuvres than for spirometric manoeuvres [8-10]. In addition, patients with asthma may have more difficulty than normal subjects in meeting reproducibility criteria for spirometry or PEF manoeuvres performed at home [11, 12]. Quality-con- trol issues are particularly important in home monitoring in asthma because short-term changes in PEF may lead to changes in medication, as the result of implementation of an asthma crisis plan by the patient.

The aim of the present study was to examine FEV1, FVC and PEF data recorded electronically at home by subjects with asthma, to identify sources of variation, including those that may not be recognized during computerized data processing, and to determine the extent to which the spirometric manoeuvres and their processing conformed with international guidelines for laboratory-based spirometry, including within-session reproducibility. The data come from a long-term clinical trial of the effects of budesonide in subjects who, at the time of entry, had poorly controlled asthma.

\section{Methods}

\section{Subjects and study design}

Eligibility criteria for the clinical trial during which this study was conducted included moderate to severe asthma as determined by symptom frequency, bronchodilator use, peak flows and reversibility of FEV1. Exclusion criteria 
included current smoking, use of long-acting $\beta_{2}$-agonists, and exacerbation of asthma or change in inhaled steroid dosage (if used) in the previous month. Baseline spirometry was carried out using a pressure differential heated pneumotach (Jaeger Masterscope version 4.17; Erich Jaeger, Wuerzburg, Germany), with predicted values taken from MorRIs et al. [13]. Analyses, unless otherwise specified, are of data collected from the first 33 subjects over two one-week periods during the run-in period and after the first 8 weeks of budesonide treatment (week 9). The protocol for the study was approved by the hospital ethics committee and written informed consent was given by all subjects.

\section{Electronic spirometry}

Subjects were instructed in the use of a hand-held turbine-style electronic diary card (EDC) (MicroMedical DiaryCard, Rochester, Kent, UK), which was used twice daily while standing, with the morning EDC session to be performed immediately upon waking. $\beta_{2}$-agonist was inhaled on demand and subjects were asked to use the EDC before medication. Five onscreen questions relating to symptoms and medication were answered, then subjects were instructed to "blow all the way out as fast as you can" in each of three prompted spirometry manoeuvres. For each manoeuvre, only PEF $\left(\mathrm{L} \cdot \mathrm{min}^{-1}\right)$ was displayed on the screen, but FEV1 and FVC were also recorded, with a resolution of $0.03 \mathrm{~L}$ and $0.01 \mathrm{~L}$, respectively. Technique with the EDC was checked at each visit. As the EDC did not permit changes to a question response once it had been entered, subjects recorded any corrections in a paper diary. Data downloaded from the EDC as Lotus 1-2-3 spreadsheets were imported into Microsoft Excel for processing using Visual Basic macro programming. Data preparation at each visit included the steps listed in table 1 .

Analysis for the present report included the following steps: 1) For each EDC session, the three manoeuvres were assigned a manoeuvre number (manoeuvre $1=$ first performed) and separate rank orders for FEV1, FVC and PEF (rank $1=$ highest value). The manoeuvre number for the highest ranked FEV1, FVC and PEF from each session was determined, and averaged over one week. 2) Sessions during which bronchoconstriction may have occurred were identified by a successive fall in FEV1 or PEF over the three manoeuvres, expressed as per cent of total sessions.

Table 1. - Steps involved in the preparation and editing of electronic dairy card (EDC) data before analysis

Scrutiny of paper diary: corrections to question responses, comments by subject about nonasthma events that may have affected results

Deletion of first 2 days of EDC data for learning effect [14]

Deletion of extra sessions and of sessions performed by someone other than the subject

Date/time record: correction for daylight saving and international travel, allocation of each session to "morning" or "evening"

Identification of outlying values from data plot and standard deviation calculation; screening of flow-volume loops for these manoeuvres

Identification of postbronchodilator sessions (inhalation of $\beta_{2}$-agonist in previous $4 \mathrm{~h}$ ) from a specific EDC question
3) Within-session reproducibility was calculated for FEV1, FVC and PEF as the absolute and percentage difference between the highest and second-highest value within each session, averaged over 1 week. The proportions of sessions fulfilling the American Thoracic Society (ATS) guide-lines for within-session reproducibility for FEV1 and FVC of $<200 \mathrm{~mL}$ [8] and the National Asthma Education Program (NAEP)/National Heart, Lung and Blood Institute (NHLBI) guidelines for PEF of $<10 \%$ [15] were recorded as percentages. 4) Short manoeuvres, in which FEV1 was equal to FVC, were expressed as per cent of total manoeuvres. 5) The average time at which EDC sessions were performed was calculated for morning and evening, and for weekdays (Monday morning to Friday morning) and weekends (Friday evening to Sunday evening), over the first 8 weeks. 6) From the clinical trial to date (22,000 subject days), nonasthma events that appeared to have influenced spirometric results were recorded.

\section{Statistical analysis}

For normally distributed variables, standard error and $95 \%$ confidence limits about the mean were calculated. The distribution of within-session reproducibility data was right-skewed and was normalized by log-transformation; the $95 \%$ confidence limits about the geometric mean were then calculated for these data. Comparison was made using paired and unpaired t-tests with a significance level of 0.05. Correlations with baseline patient data were examined using Pearson correlation coefficients for continuous data and Spearman correlation coefficients for categorical data.

\section{Results}

Baseline data for the 33 subjects are shown in table 2 . None of the subjects had previously attended an asthma clinic, and fewer than one-quarter had used a peak flow meter at any time in the previous year. An average of 12.8 sessions was available for each patient in each one-week period. Table 3 shows the improvement in spirometric data between run-in and week 9 of budesonide treatment. Morning EDC sessions were performed later on weekends than on weekdays (table 4 ), particularly by younger subjects $(\mathrm{r}=-0.63, \mathrm{p}<0.0001)$. There was wide intersubject and intrasubject variation in session times, particularly in the evenings. The earliest morning session was recorded at 03:40 $\mathrm{h}$ and the latest evening session at 05:30 h. Five subjects $(15 \%)$ recorded at least one evening session after 03:00 h (0.4\% evening sessions).

Table 2. - Baseline subject data $(n=33)$

\begin{tabular}{lc}
\hline Male n (\%) & $21(60)$ \\
Age yrs, average (range) & $40.2(18.6-67.4)$ \\
Smokers never/past n (\%) & $27(82) / 6(18)$ \\
Initial FEV1 \% pred, average $( \pm \mathrm{SE})$ & $72.1( \pm 3.2)$ \\
\hline
\end{tabular}

FEV1: forced expiratory volume in one second. 
Table 3. - Waking prebronchodilator parameters from run-in and week 9 of budesonide treatment, recorded at home on an electronic spirometer

\begin{tabular}{lrrc}
\hline & Run-in & $\begin{array}{r}\text { Week 9 of } \\
\text { budesonide }\end{array}$ & $\begin{array}{c}\text { Change } \\
\%\end{array}$ \\
\hline FEV1 L & $2.12 \pm 0.15$ & $2.83 \pm 0.18$ & $37.3 \pm 5.2^{+}$ \\
FVC L & $2.95 \pm 0.18$ & $3.71 \pm 0.20$ & $27.7 \pm 3.5^{+}$ \\
PEF L.min ${ }^{-1}$ & $345.2 \pm 19.7$ & $474.5 \pm 20.5$ & $43.1 \pm 5.5^{+}$ \\
\hline
\end{tabular}

Data are shown as mean \pm sE. $n=33$ subjects. FEV1: forced expiratory volume in one second; FVC: forced vital capacity; PEF: peak expiratory flow. ${ }^{+}: \mathrm{p}<0.0001$ for change in each parameter between run-in and week 9 .

Table 5 lists sources of variation in electronic spirometric data that were identified during the clinical trial, with typical spirometric effects listed in table 6 . The most common artefactual data $(<1 \%$ of manoeuvres) were due to turbine movement before expiration, with typical results of FEV1 $0.3 \mathrm{~L}, \mathrm{FVC} 0.3 \mathrm{~L}$ and PEF $1 \mathrm{~L} \cdot \mathrm{min}^{-1}$. During runin, PEF peaked earlier in EDC sessions than did FEV $1(\mathrm{p}<$ 0.02) (fig. 1). As a result, average PEF over 1 week was higher if the maximum PEF for each session was used than if PEF was taken from the curve with the highest FEV1 (345 L· $\mathrm{min}^{-1}$ compared with $338 \mathrm{~L} \cdot \mathrm{min}^{-1}, \mathrm{p}<0.0001$ ). This difference was still seen at week 9. During run-in, successive falls in FEV1 or PEF were demonstrated in $15.3 \%$ (SD 12.8 ) and $16.2 \%$ (SD 11.8) of EDC sessions, respectively, with no significant change at week 9 ( $p>0.4)$ and no association with age, sex, smoking status or baseline lung function.

Within-session reproducibility of FEV1, FVC and PEF during the first week of run-in and in week 9 of budesonide treatment is shown in figure 2 , with the proportions of sessions complying with the ATS [8] and NAEP/NHLBI [15] guidelines in figure 3 . No significant correlation was seen between within-session reproducibility and baseline lung function, despite asthma being poorly controlled at entry. During electronic spirometric monitoring in the run-in period, four subjects on $>10 \%$ of occasions recorded manoeuvres in which $\mathrm{FEV}_{1}$ was equal to $\mathrm{FVC}$, i.e. which presumably lasted for $<1 \mathrm{~s}$, but flow-volume loops did not resemble "spitting" with an artefactually high PEF, as can occur with a PEF manoeuvre [19]. Software supplied with the EDC calculated the duration of expiration for these manoeuvres as between 2.3 and $4.5 \mathrm{~s}$. In two subjects short manoeuvres persisted despite further demonstration of the correct technique at subsequent visits.

Table 4. - Times at which morning and evening sessions were recorded on weekdays and weekends during the first eight-week study period

\begin{tabular}{|c|c|c|c|c|}
\hline & \multicolumn{2}{|c|}{ Morning } & \multicolumn{2}{|c|}{ Evening } \\
\hline & WD & WE & WD & WE \\
\hline $\begin{array}{l}\text { Session time, } \\
\text { average }\end{array}$ & $07: 11 \mathrm{~h}$ & $08: 32 \mathrm{~h}^{+}$ & $20: 52 \mathrm{~h}$ & $21: 01 \mathrm{~h}$ \\
\hline $\begin{array}{l}\text { SD of session times } \\
\text { for each subject, min, } \\
\text { average }(95 \% \mathrm{CL})\end{array}$ & $\begin{array}{c}53 \\
(45,60)\end{array}$ & $\begin{array}{c}85^{+} \\
(74,95)\end{array}$ & $\begin{array}{c}71^{+} \\
(61,81)\end{array}$ & $\begin{array}{c}101^{+} \\
(90,112)\end{array}$ \\
\hline
\end{tabular}

Weekdays (WD): Monday morning to Friday morning; weekends (WE): Friday evening to Sunday evening. $n=33$ subjects. $+: \mathrm{p}<0.0001$ compared with weekday mornings. Morning sessions were performed later at weekends, and were within a narrower time range than evening sessions. CL: confidence limits.
Table 5. - Potential sources of variation in electronic spirometric data

Instrument problems: sporadic* or systemic (table 6) Ambient conditions: temperature, altitude [16], wind (table 6)

Software: data recording, storage and downloading; calculated PEF indices

Intrasubject variation

Extraneous data: EDC used by someone else*

Erroneous data: mistakes in symptom or medication data entry by patient*

Time of session: variation in time of waking, hence time of acrophase, between/within subjects [17]; elapsed time after waking* [18]

Unsupervised manoeuvre technique: learning effect (2-3 days); short manoeuvres; submaximal effort/ painful conditions (table 6$)^{*}$; within-session reproducibility.

$\beta_{2}$-agonist use within $4 \mathrm{~h}$ prior to EDC session*

Processing problems

Allocation of session to "morning" or "evening": times of morning and evening sessions may overlap* evening session performed after midnight will carry the next day's date*

adjust for international travel and daylight saving*

Choice of "best" manoeuvre: choose highest PEF and highest FEV1 unless artefactual

These variations must be taken into account during processing. Items marked with an asterisk $\left(^{*}\right)$ may be able to be clarified from an accompanying paper diary. PEF: peak expiratory flow; EDC: electronic diary card; FEV1: forced expiratory volume in one second.

Approximately two corrections per subject per eightweek study period were made in the paper diary for symptom or medication responses. Many subjects also recorded nonasthma events that they believed had influenced their spirometric results (table 6). Reduction in PEF during these events was usually in the order of $20-50 \mathrm{~L} \cdot \mathrm{min}^{-1}$, and occurred more often than reduction in FEV1. Multiple episodes of increased PEF and FEV1 were seen for one subject during a period when the subject consistently phonated during spirometric manoeuvres. This observation could be reproduced by the subject in the clinic on the turbine device but not on simultaneous pneumotach recordings.

\section{Discussion}

In this study of subjects with asthma who were performing home electronic spirometric monitoring during a clinical trial, it was demonstrated that considerable data editing was needed to identify and correct for confounding factors (table 5) before routine computerized analysis could be carried out. Within-session reproducibility in most sessions fell well within the international guidelines for supervised laboratory spirometry, and for FEV 1 and PEF did not change significantly with substantial improvement in asthma severity.

\section{Quality of data obtained from electronic home monitoring}

While errors due to falsification of data and incorrect transcription are avoided with electronic monitoring, the data are still subject to error. Several sources of intrasubject variation were recognized which could not be identified from the electronic record alone, but which could 
Table 6. - Nonasthma events that appeared to have caused changes in spirometric parameters during the clinical trial

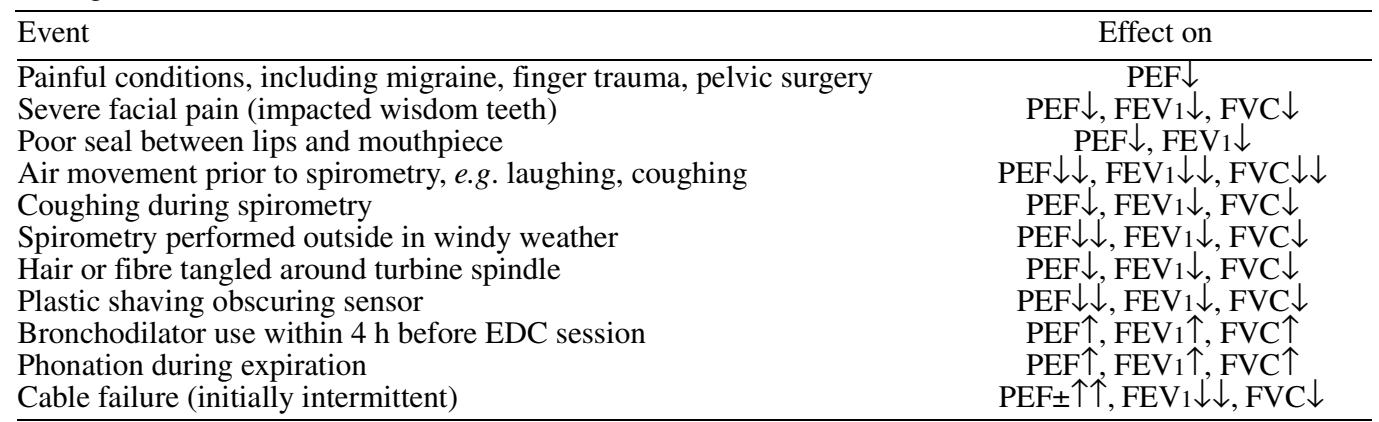

Double arrows indicate a value that was clearly nonphysiological; single arrows indicate a change that could have been mistaken for a change in asthma severity (increase/decrease shown). PEF: peak expiratory flow; FEV1: forced expiratory volume in one second; FVC: forced vital capacity; EDC: electronic dairy card.

often be clarified from entries made at the time in the accompanying paper diary (tables 5 and 6). Such a paper diary should be regarded as an essential accompaniment to an electronic diary, in order to avoid inappropriate changes in asthma medication because of nonasthma events. With a conventional mechanical peak flow meter and paper diary, some editing is performed by the subject, unbeknown to the physician; for example, exclusion of manoeuvres performed by someone other than the subject.

A small proportion of outlying values were due to instrument artefact (table 6). The most common were produced by air movement near the mouthpiece, e.g. due to laughing. Patients using low-resistance turbine spirometers should be advised not to use them outdoors or near a fan. Tangling of hair around the turbine spindle caused spirometric changes which resembled asthma exacerbations in three subjects; this was identified by failure of the turbine vane to spin freely. This possibility should be kept in mind if a fall in PEF occurs in the absence of asthma symptoms, and patients should be asked to keep turbine devices covered between sessions. Cable failure, which occurred in $10 \%$ of the electronic spirometers, was identified by initially intermittent marked reductions in PEF and FEV1,

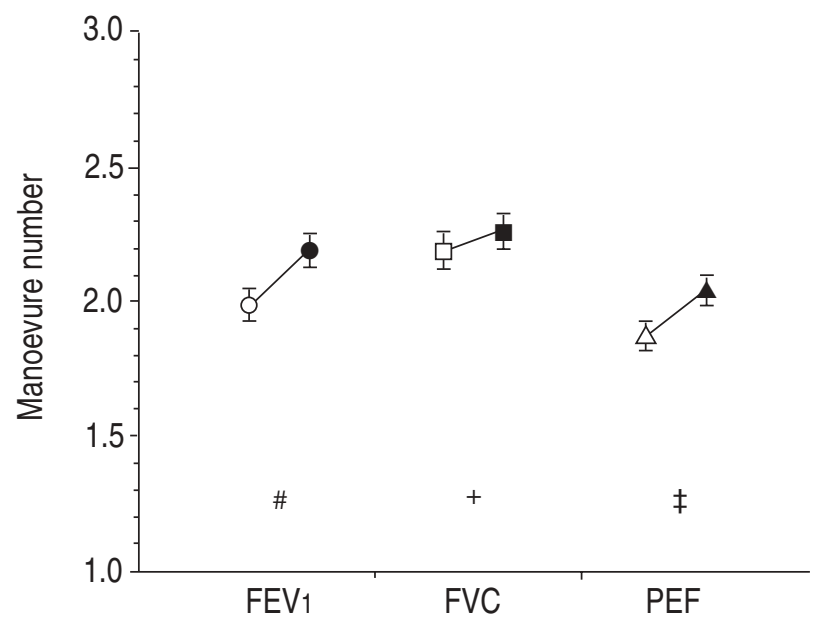

Fig. 1. - Average manoeuvre number, out of three manoeuvres, of the highest forced expiratory volume in one second (FEV1), forced vital capacity (FVC) and peak expiratory flow (PEF) in each electronic monitoring session during run-in (open symbols) and after 8 weeks of budesonide (closed symbols). The highest PEF occurred earlier in the session than did the highest FEV1. By week 9, the highest value for FEV 1 and PEF occurred later in the session than during run-in. Values are shown as mean \pm SEM. \#: $\mathrm{p}=0.002 ;{ }^{+} \mathrm{p}=0.1 ;$ : $\mathrm{p}=0.003$. but with occasional very high PEF values. This problem has apparently been addressed in the design of a subsequent model. The observation of occasional artefactual increases in PEF is a concern, given that usual processing methods will select the best value for a session on the assumption that this is likely to represent the most physiologically valid result.

\section{Quality of spirometric manoeuvres in home monitoring}

Because the electronically recorded spirometric sessions were unsupervised, the only information about the quality of the expiratory manoeuvres was that available from the spirometric results and the flow-volume loops. Visual scanning of flow-volume loops is cumbersome and subjective and, in this study, was reserved for screening of outlying values. Data were also screened for manoeuvres in which FEV1 and FVC were equal. Only two subjects continued to record such short manoeuvres on $>15 \%$ of occasions at home, despite satisfactory supervised manoeuvres at study visits. Results for FEV 1 and FVC from such manoeuvres must be regarded as unreliable.

Although the reliability and reproducibility of FEV1 and FVC recorded at home have previously been studied in healthy volunteers, $\alpha_{1}$-antitrypsin deficiency [20] and after lung transplantation [21], patients with poorly controlled asthma might be expected to be less able to satisfy within-session reproducibility criteria [11]. In one study in asthmatics and normal subjects, within-session reproducibility of FEV1 was within $5 \%$ in $75 \%$ of sessions [22]. In the present study, the upper $95 \%$ confidence limits for within-session reproducibility of FEV1 and FVC fell well within the ATS guideline of $200 \mathrm{~mL}$ for supervised manoeuvres [8] both during run-in and at week 9 . This criterion was satisfied for FEV1 in $90 \%$ of sessions. This excellent reproducibility was not due to previous experience with respiratory function testing, as most subjects had not monitored PEF before. Absolute reproducibility of FEV1 (L) did not change significantly after budesonide treatment (fig. 2a), but percentage reproducibility improved significantly, to $3.2 \%$ (fig. 2b), because of a large increase in average FEV1 (table 3). This suggests that the current European Respiratory Society recommendation for reproducibility of FEV1 of $5 \%$ or $100 \mathrm{~mL}$, whichever is the greater [9], would be less easily satisfied by patients with significant airway obstruction [23]. Reproducibility of FVC, expressed both in litres and as a percentage, im- 

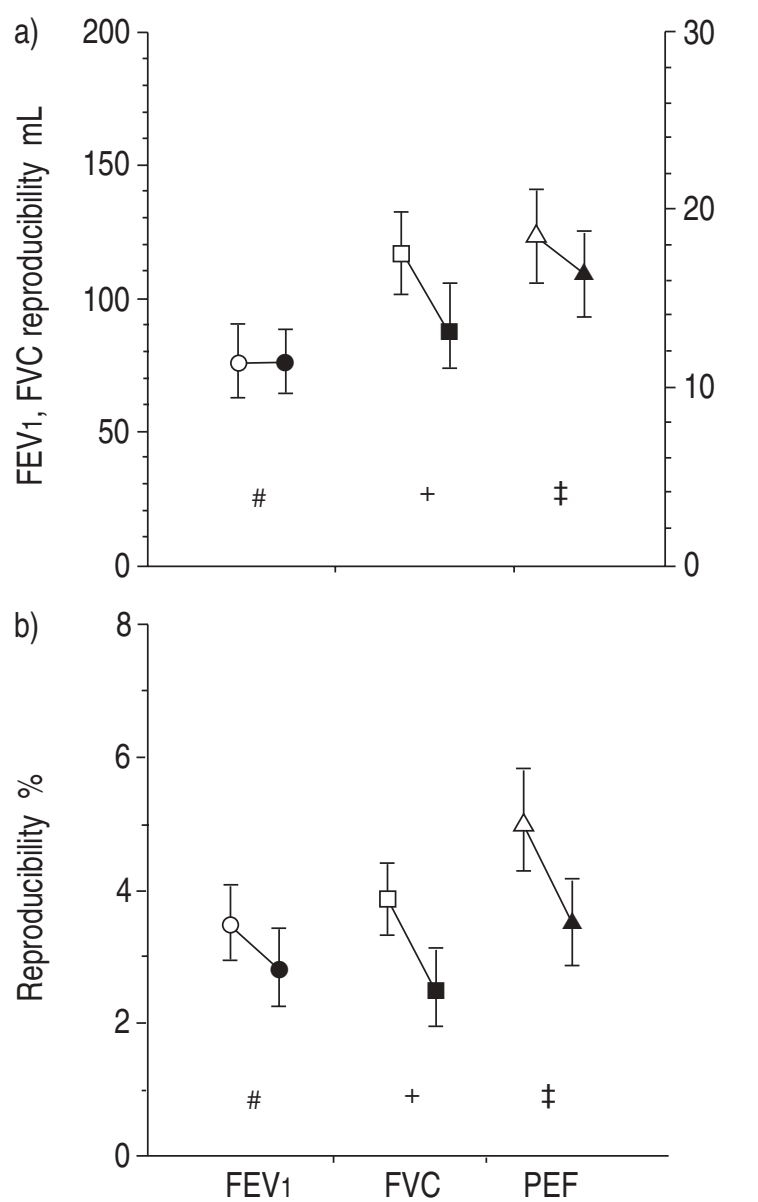

Fig. 2. - Average within-session reproducibility (best value - second best value of each electronic monitoring session over a one week period) expressed: a) in $\mathrm{mL}$ (forced expiratory volume in one second $(\mathrm{FEV} 1)$ and forced vital capacity $(\mathrm{FVC})$ ) and $\mathrm{L} \cdot \mathrm{min}^{-1}$ (peak expiratory flow (PEF)); and b) as a percentage of the best value, during run-in ( $\square$ ) and after 8 weeks of budesonide $(\bullet)$. Absolute within-session reproducibility for FEV1 and PEF did not change significantly despite large improvements in FEV1 and PEF. Values are shown as mean \pm SEM. a) \#: $\mathrm{p}=1.0 ;+\mathrm{p}=0.003 ;+\mathrm{p}=0.2 ; \mathrm{b})$ \#: $\mathrm{p}=0.02 ;^{+}: \mathrm{p}=0.00002 ; \mathrm{*}=0.0003$.

proved significantly by week 9 , possibly because of a reduction in fatigue with improvement in airway obstruction.

Reproducibility of PEF in the present study was much better than has been expected from home PEF monitoring in the past [12], possibly because of the spirometric manoeuvre or the requirement to compare waking PEF with a trigger point. The upper $95 \%$ confidence limit for withinsession reproducibility of PEF $\left(21.4 \mathrm{~L} \cdot \mathrm{min}^{-1}(5.8 \%)\right.$ during run-in) fell well within the NAEP/NHLBI recommendation of $10 \%$ [15] and the European Respiratory Society recommendation of $40 \mathrm{~L} \cdot \mathrm{min}^{-1}$ [19]. A reproducibility target of $20 \mathrm{~L} \cdot \mathrm{min}^{-1}$ should be achievable by most patients with asthma and is easier to explain than a percentage target. A percentage target would also be less easily reached by females or shorter patients or during periods of increased airway obstruction. As with supervised spirometry, poorly reproducible spirometric data should not be excluded in processing, but the reproducibility achieved should be noted [8]

A successive fall in FEV1 or PEF through the three manoeuvres in an EDC session, indicating possible manoeuvre-induced bronchoconstriction, would be expected

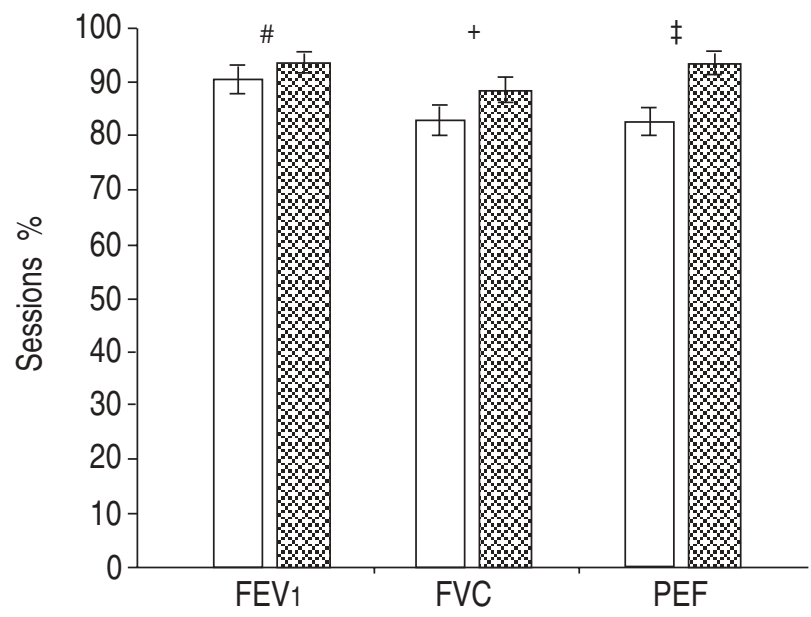

Fig. 3. - Percentage of electronic monitoring sessions which complied with American Thoracic Society (ATS) guidelines for within-session reproducibility of forced expiratory volume in one second (FEV1) and forced vital capacity (FVC) $(<200 \mathrm{~mL})$ [8] and National Asthma Education Program (NAEP)/National Heart, Lung and Blood Institute (NHLBI) recommendation for within-session reproducibility of peak expiratory flow (PEF) $(<10 \%)$ [15], during run-in $(\square)$ and after 8 weeks of budesonide treatment ( $\$)$. Although spirometry sessions were unsupervised, most fell within the guidelines for reproducibility of supervised manoeuvres. Values are shown as mean \pm SEM. \#: $\mathrm{p}=0.3$; +: $\mathrm{p}=0.1 ; \div \mathrm{p}=0.0003$.

to occur by chance alone in up to $1 / 6(17 \%)$ of sessions. The rate of successively falling PEF or FEV 1 in the present study was not significantly different from that expected by chance, even when asthma was poorly controlled [12], $c f$ [11], and did not occur more frequently in subjects with greater airway obstruction. The fact that the highest $\mathrm{PEF}$ and FEV1 occurred later in week 9 sessions than during run-in sessions may have been partly due to the psychological effect of having a PEF trigger point, as no trigger point was used during the run-in period.

\section{Quality control of analysis of electronic diary card data}

By contrast with other electronic monitoring systems, such as Holter monitoring, the software packaged with the EDC used in this study does not perform any analysis apart from the erroneous calculation of duration of expiration. This may be an advantage because of the difficulty in designating EDC sessions as "morning" or "evening", with implications for derived PEF indices. Obviously, if a patient performs electronic monitoring while travelling across time-zones the date/time record must be adjusted. However, several subjects in the present study, who were not shift-workers, demonstrated wide variation in session times (table 4), with some evening sessions performed in the early morning, after the time of some morning sessions. Designation of sessions performed after 03:00 h as "morning" sessions would have resulted in misclassification of only $0.4 \%$ of evening sessions, but these were distributed among $15 \%$ of subjects. In occupational asthma, with multiple PEF sessions each day, computerized division of the date/time record has been developed [24, 25], but for twice-daily electronic monitoring it may be necessary to include a specific question to allow separation of morning and evening sessions. The present study was limited by the fact that there was no way of checking that the 
morning EDC session had been performed immediately upon waking. Delaying the morning session by even 15 min after waking can significantly alter FEV1 and PEF results [18]. Specifying particular time windows for morning and evening PEF sessions, as in some clinical trial protocols, may possibly increase rather than decrease variation due to circadian rhythm, because of intrapatient and interpatient variability in the time of waking [17].

Analysis of spirometric data recorded at home should always take into account whether $\beta_{2}$-agonist has been inhaled within the previous $4 \mathrm{~h}$, as patients may not have been able to withhold bronchodilator until after their scheduled EDC session and inclusion of postbronchodilator values can significantly change PEF indices [26].

The ATS guidelines for selection of the "best" manoeuvre from supervised spirometry recommend that PEF should be taken from the curve with the greatest FEV1 + FVC [8]. From the present results, this does not appear to be appropriate for unsupervised spirometry because of the risk of shortened manoeuvres and because the highest PEF and FEV1 did not occur in the same manoeuvre. Some electronic monitoring devices store only the "best" manoeuvre, presumably to maximize storage capacity. The criteria by which the "best" PEF or FEV1 is selected by a device should be scrutinized to ensure that they are scientifically valid and physiologically appropriate for the subject group.

Patients with poorly controlled asthma can perform spirometry at home without significant risk of bronchoconstriction and with reproducibility well within guidelines for supervised spirometry. Because of the possibility of spirometric results being influenced by equipment faults or nonasthma events which are apparent to the subject at the time, and because incorrectly entered diary card responses may not be able to be changed by the subject, a paper diary continues to be a necessary accompaniment to an electronic diary card. Despite the attractiveness of paperless home monitoring and the assumption that electronically collected spirometric data are cleaner than a conventional paper peak expiratory flow record, the quality-control processes involved in the editing and analysis of data from home spirometric monitoring are complex. These quality-control issues are particularly important in clinical asthma management, because day-to-day variations in peak expiratory flow data may lead to medication changes as a result of the implementation of an asthma crisis plan.

Acknowledgement: The authors would like to thank N. Brown for help with the graphics.

\section{References}

1. Lebowitz MD. The use of peak expiratory flow rate measurements in respiratory disease. Pediatr Pulmonol 1991; 11: 166-174.

2. Lebowitz MD, Quanjer PH. Peak expiratory flow. Eur Respir J 1997; 10: Suppl. 24, 1s-83s.

3. Fishwick D, Beasley R. Use of peak-flow based selfmanagement plans by adult asthmatic patients. Eur Respir J 1996; 9: 861-865.

4. Hyland ME, Kenyon C, Allen R, Howarth P. Diary keeping in asthma: comparison of written and electronic methods. Br Med J 1993; 306: 487-489.

5. Chowienczyk P, Parkin D, Lawson C, Cochrane G. Do asthmatic patients correctly record home spirometry mea- surements? Br Med J 1994; 309: 1618.

6. Bright P, Burge PS. The diagnosis of occupational asthma from serial measurements of lung function at and away from work. Thorax 1996; 51: 857-863.

7. Nelson S, Gardner R, Crapo R, Jensen R. Performance evaluation of contemporary spirometers. Chest 1990; 97 : 288-297.

8. American Thoracic Society. Standardization of spirometry, 1994 update. Am J Respir Crit Care Med 1995; 152: $1107-1136$.

9. Quanjer PH, Tammeling GJ, Cotes JE, et al. Lung volumes and forced ventilatory flows. Eur Respir J 1993; 6: $5-40$.

10. Enright PL, Lebowitz MD, Cockroft DW. Physiologic measures: pulmonary function tests. In: NIH Workshop on measures for use in asthma clinical research. Am J Respir Crit Care Med 1994; 149: S1-S8.

11. Ng'Ang'a L, Ernst P, Jaakkola M, et al. Spirometric lung function. Distribution and determinants of test failure in a young adult population. Am J Respir Crit Care Med 1992; 145: 48-52.

12. Enright PL, Sherrill DL, Lebowitz MD. Ambulatory monitoring of peak expiratory flow. Reproducibility and quality control. Chest 1995; 107: 657-661.

13. Morris JF, Koski A, Temple WP, et al. Fifteen-year interval spirometric evaluation of the Oregon predictive equations. Chest 1989; 92: 123-127.

14. Quackenboss JJ, Liebowitz MD, Krzyzanowski M. The normal range of diurnal changes in peak expiratory flow rates. Relationship to symptoms and respiratory disease. Am Rev Respir Dis 1991; 143: 323-330.

15. Cherniak R, Hurd S, for the NAEP and NHLBI. Statement on technical standards for peak flow meters. NIH Publication No. 92-2113a, 1992, US Dept of Health and Human Services.

16. Pedersen OF, Miller MR, Sigsgaard T, et al. Portable peak flow meters: physical characteristics, influence of temperature, altitude and humidity. Eur Respir J 1994; 7: 991-997.

17. Cinkotai F, Sharpe T, Gibbs A. Circadian rhythms in peak expiratory flow rate in workers exposed to cotton dust. Thorax 1984; 39: 759-765.

18. Eckert B, Mitchell C, Brennan T, Huxham G. Diurnal variation in airway calibre: influence of time of measurement. Aust NZ J Med 1995; 25: A453.

19. Quanjer PH, Lebowitz MD, Gregg I, et al. Peak expiratory flow: conclusions and recommendations of a Working Party of the European Respiratory Society. Eur Respir J 1997; 10: Suppl. 24, 2s-8s.

20. Madsen F, Ulrik C, Dirksen A, et al. Patient-administered sequential spirometry in healthy volunteers and patients with $\alpha_{1}$-antitrypsin deficiency. Respir Med 1996; 90: 131138.

21. Finkelstein S, Lindgren B, Prasad B, et al. Reliability and validity of spirometry measurements in a paperless home monitoring diary program for lung transplantation. Heart Lung 1993; 22: 523-533.

22. Troyanov S, Ghezzo H, Cartier A, Malo J-L. Comparison of circadian variations using FEV 1 and peak expiratory flow rates among normal and asthmatic subjects. Thorax 1994; 49: 775-780.

23. Hankinson J, Bang K. Acceptability and reproducibility criteria of the American Thoracic Society as observed in a sample of the general population. Am J Respir Crit Care Med 1991; 143: 516-521.

24. Burge P. Use of serial peak flow measurements in the diagnosis of occupational asthma. Occup Med 1993; 8: 279-294.

25. Newton D, Gannon P, Burge P, et al. An evaluation of a computer based system to divide peak expiratory flow records. Eur Respir J 1992; 5: Suppl. 15, 403s.

26. Reddel HK, Ware SI, Salome CM, et al. Standardization of ambulatory PEF monitoring - the importance of recent $\beta_{2}$-agonist inhalation. Eur Respir J 1998; 12: 309-314. 